\title{
Bearing capacity of foundations on rock mass using the method of characteristics
}

\author{
Amin Keshavarz ${ }^{1}$ (D) । Jyant $\operatorname{Kumar}^{2}$ (])
}

\author{
${ }^{1}$ School of Engineering, Persian Gulf \\ University, Bushehr, Iran \\ ${ }^{2}$ Civil Engineering Department, Indian \\ Institute of Science, Bangalore, India \\ Correspondence \\ Jyant Kumar, Civil Engineering \\ Department, Indian Institute of Science, \\ Bangalore 560012, India. \\ Email: jkumar@iisc.ac.in
}

\begin{abstract}
Summary
The method of stress characteristics has been used for computing the ultimate bearing capacity of strip and circular footings placed on rock mass. The modified Hoek-and-Brown failure criterion has been used. Both smooth and rough footing-rock interfaces have been modeled. The bearing capacity has been expressed in terms of nondimensional factors $N_{\sigma 0}$ and $N_{\sigma}$, corresponding to rock mass with (1) $\gamma=0$ and (2) $\gamma \neq 0$, respectively. The numerical results have been presented as a function of different input parameters needed to define the Hoek-and-Brown criterion. Slip line patterns and the pressure distribution along the footing base have also been examined. The results are found to compare generally well with the reported solutions.
\end{abstract}

\section{KEYWORDS}

bearing capacity, failure, foundations, Hoek-Brown criterion, rocks, the method of characteristics

\section{1 | INTRODUCTION}

The determination of the bearing capacity of footings on rocks forms an important issue especially while (1) laying foundations on weak rocks, (2) estimating the ultimate tip resistance of piles placed on rocks, and (3) designing dams' foundations. As compared with foundations in soils, only limited studies seem to have been available in literature to compute the bearing capacity of foundations on rock mass. Serrano and Olalla used the Hoek-and-Brown (HB) failure criterion to compute the ultimate bearing capacity of strip footings placed on a weightless rock medium. ${ }^{1}$ Serrano et al also used the modified HB criterion to evaluate the bearing capacity of a strip footing placed on a weightless rock medium. $^{2}$ By using the original HB criterion, Yang et al performed a lower-bound limit analysis to compute the bearing capacity of a strip footing placed on a weightless rock medium. ${ }^{3}$ Merifield et al used the limit analysis in combination with optimization and finite elements to compute the ultimate bearing capacity of strip footings on rock mass. ${ }^{4}$ In this analysis, the modified HB failure criterion was used to compute the ultimate bearing capacity. By using the original and modified HB failure criteria, Zhou et al applied the slip line method to calculate the bearing capacity of strip footings placed on rock mass. ${ }^{5}$ Clausen used the standard displacement-based elastoplastic finite element approach to compute the ultimate bearing capacity of circular footings laid on rock mass. ${ }^{6}$ Chakraborty and Kumar evaluated the ultimate bearing capacity of circular footings on rock mass by using the lower-bound theorem of the limit analysis. ${ }^{7}$ In this work, the modified HB failure criterion was used but by assuming a constant value of the exponent, $a=0.5$, which provides an overestimation of the bearing capacity for lower values of the geological strength index $(G S I)$. Keshavarz et al used the method of stress characteristics to evaluate the seismic bearing capacity of strip footings placed over rock mass. ${ }^{8}$ The study was, however, based on the original HB failure criterion, and moreover, it did not consider a formation of a nonplastic wedge, which invariably occurs for a rough footing base. As compared with available solutions for strip footings, not many theories seem to be existing for finding the bearing capacity of 
circular footings placed on rock mass. The studies of Clausen ${ }^{6}$ and Chakraborty and Kumar ${ }^{7}$ seem to be perhaps the only ones for the circular foundations.

The objective of the present study is to evaluate the ultimate bearing capacity of strip and circular footings placed on rock mass by using the method of stress characteristics. The modified HB failure criterion has been used. The analysis has been performed for both smooth and rough footing-rock interfaces. The effects of different material input parameters needed to define the modified HB failure criterion completely on the resulting bearing capacity, pressure distribution, and failure patterns have been examined. The results obtained from the analysis have been compared with that available from the literature.

\section{2 | MODIFIED HB FAILURE CRITERION}

The modified HB failure criterion ${ }^{9}$ can be written as

$$
\frac{\sigma_{1}-\sigma_{3}}{\sigma_{\mathrm{c}}}=\left(m_{\mathrm{b}} \frac{\sigma_{3}}{\sigma_{\mathrm{c}}}+s\right)^{a}
$$

where (1) $\sigma_{\mathrm{c}}$ defines the uniaxial compressive strength of the intact rock mass; (2) $\sigma_{1}$ and $\sigma_{3}$ represent the major and minor principal stresses, respectively; and (3) $a, m_{\mathrm{b}}$, and $s$ represent the dimensionless input material parameters, which are defined as follows ${ }^{10}$ :

$$
\begin{aligned}
& a=\frac{1}{2}+\frac{1}{6}\left\{\exp \left(\frac{-G S I}{15}\right)-\exp \left(\frac{-20}{3}\right)\right\}, \\
& m_{\mathrm{b}}=m_{i} \exp \left(\frac{G S I-100}{28-14 D}\right), \\
& s=\exp \left(\frac{G S I-100}{9-3 D}\right) .
\end{aligned}
$$

In the above expressions, GSI refers to the geological strength index and the factor $D$ represents the disturbance of the rock mass, the value of which varies from 0 for an undisturbed rock mass to 1 for very disturbed rock mass. Unless otherwise exclusively specified, the value of $D$ has been assumed to be 0 in the present analysis.

\section{3 | EQUILIBRIUM EQUATIONS}

All the basic equations have been presented only for an axisymmetric case. However, these equations can be easily transformed to an equivalent plane strain case by simply replacing the basic stress variables $\sigma_{r}, \sigma_{z}$, and $\tau_{r z}$ with $\sigma_{x}, \sigma_{y}$, and $\tau_{x y}$, respectively. The axisymmetric problem also involves an additional circumferential stress variable $\sigma_{\theta}$; on the basis of the Harr-Von Karman hypothesis, the value of $\sigma_{\theta}$ has been assumed to be equal to the minor principal stress $\sigma_{3}$. With reference to Figure 1A, for an axisymmetric case in an $r$ - $z$ plane, the equilibrium equations are given as

$$
\begin{aligned}
& \frac{\partial \sigma_{r}}{\partial r}+\frac{\partial \tau_{r z}}{\partial z}=f_{r}, \\
& \frac{\partial \sigma_{z}}{\partial z}+\frac{\partial \tau_{r z}}{\partial r}=f_{z} .
\end{aligned}
$$

Here, the parameters $f_{r}$ and $f_{z}$ are defined by the following expressions:

$$
\begin{aligned}
& f_{r}=-\frac{n}{r}\left(\sigma_{r}-\sigma_{\theta}\right), \\
& f_{z}=-\gamma-\frac{n}{r} \tau_{r z} .
\end{aligned}
$$




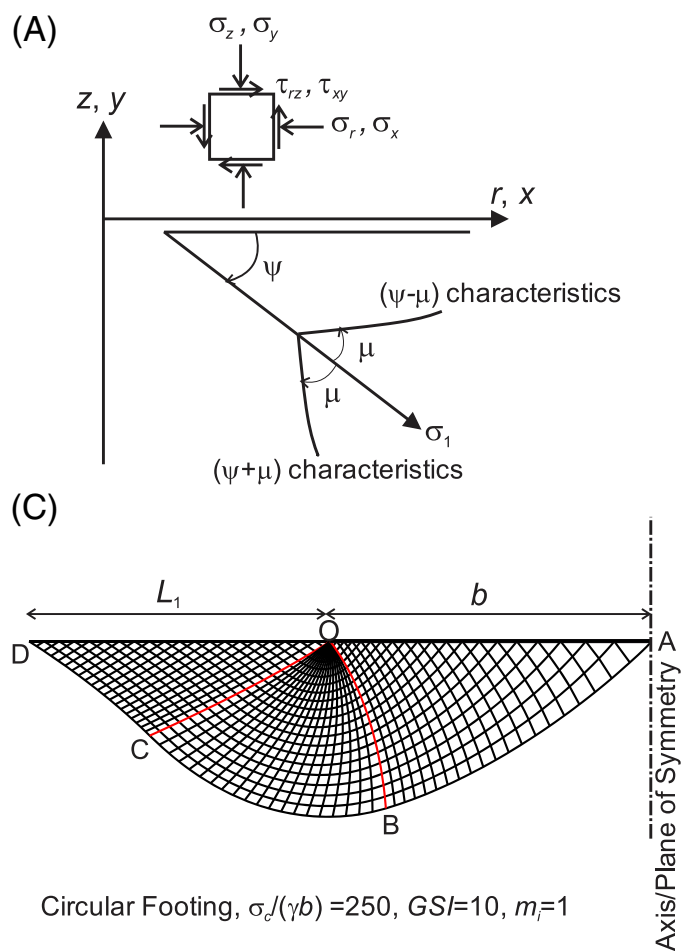

(B)

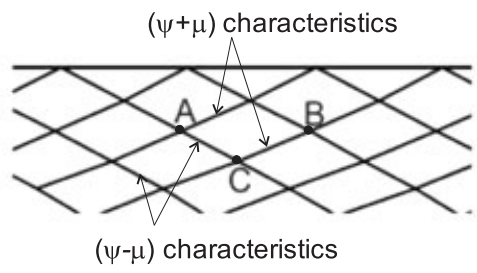

(D)

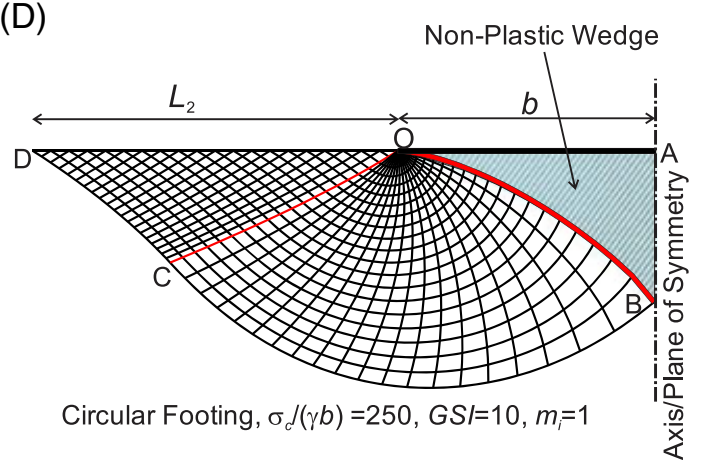

FIGURE 1 A, Definition of stress variables and stress characteristics. B, Finding unknown variables at the point C from the known variables at points A and B. C, Characteristic patterns for a smooth footing. D, Characteristic patterns for a rough footing [Colour figure can be viewed at wileyonlinelibrary.com]

The value of $n$ in Equation 4 becomes equal to 0 and 1, corresponding to plane strain and axisymmetric cases, respectively, and $\gamma$ forms the unit weight of the rock mass.

The generalized failure criterion for a homogenous medium can be written in the following form ${ }^{11}$ :

$$
f\left(\sigma_{z}, \sigma_{r}, \tau_{r z}\right)=R-F(p, \psi)=0,
$$

where $p=\sigma_{r}+\sigma_{z} / 2, R$ is the radius of the Mohr circle, and the parameter $\psi$ represents the angle between the positive $r$ axis and the direction of the major principal stress $\left(\sigma_{1}\right)$. On the basis of the Mohr circle, the 3 basic stress variables $\left(\sigma_{r}, \sigma_{z}\right.$, and $\tau_{r z}$ ) are written in terms of 2 stress variables as

$$
\begin{aligned}
& \sigma_{r}=p+R \cos 2 \psi, \\
& \sigma_{z}=p-R \cos 2 \psi, \\
& \tau_{r z}=\mathrm{R} \sin 2 \psi .
\end{aligned}
$$

With Equations 3 and 6, the associated expressions that are applicable along 2 different families of characteristics are established $^{12}$ :

- Along the $(\psi+\mu)$ characteristics:

$$
\mathrm{d} z / \mathrm{d} r=\tan (\psi-m+\mu)
$$

$$
\frac{\sin 2(m+\mu)}{\cos 2 m} \mathrm{~d} p+\frac{2 R}{\cos 2 m} \mathrm{~d} \psi=(\mathrm{d} r \sin 2 \mu-\mathrm{d} z \cos 2 \mu) f_{r}+(\mathrm{d} r \cos 2 \mu+\mathrm{d} z \sin 2 \mu) f_{z}
$$


- Along the $(\psi-\mu)$ characteristics:

$$
\begin{gathered}
\mathrm{d} z / \mathrm{d} r=\tan (\psi-m-\mu) \\
\frac{\sin 2(m-\mu)}{\cos 2 m} \mathrm{~d} p+\frac{2 R}{\cos 2 m} \mathrm{~d} \psi=-(\mathrm{d} r \sin 2 \mu+\mathrm{d} z \cos 2 \mu) f_{r}+(\mathrm{d} r \cos 2 \mu-\mathrm{d} z \sin 2 \mu) f_{z}
\end{gathered}
$$

where

$$
\begin{aligned}
& \tan 2 m=\frac{1}{2 R} \frac{\partial R}{\partial \psi} \\
& \cos 2 \mu=\cos 2 m \frac{\partial R}{\partial p}
\end{aligned}
$$

After algebraic simplifications, Equation 11 can be rewritten as

$$
\frac{R}{\beta_{a}}\left(1+(1-a)\left(\frac{R}{\beta_{a}}\right)^{k}\right)=\frac{p}{\beta_{a}}+\zeta_{a}
$$

Here,

$$
\zeta_{a}=\frac{s}{m_{\mathrm{b}} A_{a}} ; \quad \beta_{a}=A_{a} \sigma_{\mathrm{c}} ; \quad k=\frac{1-a}{a} ; A_{a}{ }^{k}=\frac{m_{\mathrm{b}}(1-a)}{2 \frac{1}{a}}
$$

By using Equations 11 and 12, the values of $m$ and $\mu$ can be computed as

$$
m=0 ; \quad \mu=0.5 \cos ^{-1}\left(\frac{1}{1+(1-a)\left(\frac{R}{\beta_{a}}\right)^{k}(1+k)}\right) .
$$

From the rock mass properties and the value of $p$, one can calculate $R$ on the basis of Equation 12 by using the Newton-Raphson method. In the method of stress characteristics, each point has 4 basic variables, namely, $r, z, p$, and $\psi$ : (1) the first 2 variables $r$ and $z$ provide the location of the point and (2) the remaining 2 variables, which are $p$ and $\psi$, provide the corresponding state of stress at failure. With reference to Figure 1B, the 4 unknown variables for point $C$ in the stress characteristics network can be found from the known values of the associated parameters from the previous points A and $\mathrm{B}$, where $\mathrm{AC}$ and $\mathrm{BC}$ refer to the $(\psi-\mu)$ and $(\psi+\mu)$ characteristics, respectively.

A trial-and-error procedure needs to be used to establish point $\mathrm{C}$ and its corresponding state of stress from Equations 7 to 10. In the first iteration, the stress variables for point $C$ are first assumed to be equal to the mean of the corresponding values at points B and A. The new values are then established at point $C$. These obtained values are then used again to update the results. This procedure is continued until the difference between the variables' values between the current and previous iterations becomes less than $0.0001 \%$.

\section{4 | SOLUTION PROCEDURE}

\section{1 | Smooth footing}

Figure 1C shows the stress characteristics patterns for a smooth footing. In this Figure, OA defines the footing base, and the parameter $b$ refers to (1) the footing radius for a circular footing and (2) half the footing width for a strip footing. A uniform surcharge pressure $q$ is prescribed along the boundary OD. Along this boundary, the normal stress $\sigma_{0}$ becomes equal to $q$ and the shear stress $\tau_{0}$ is 0 . Accordingly, the value of $\psi$ along this boundary $\left(\psi_{0}\right)$ becomes equal to 0 . By using the Mohr stress circle, one can write 


$$
R_{0}=\sqrt{\left(p_{0}-\sigma_{0}\right)^{2}+\tau_{0}}
$$

Therefore, $R_{0}=p_{0}-q$ and Equation 12 along the boundary OD can be written as

$$
\frac{p_{0}-q}{\beta_{a}}\left\{1+(1-a)\left(\frac{p_{0}-q}{\beta_{a}}\right)^{k}\right\}=\frac{p_{0}}{\beta_{a}}+\zeta_{a} .
$$

The value of the mean stress along this boundary $p_{0}$ can be obtained by solving Equation 16 . This equation is then solved by using the Newton-Raphson iterative technique.

Along the footing-rock interface boundary (boundary OA in Figure 1C), the normal stress $q_{f}$ is unknown. Along the smooth footing base, the direction of $\sigma_{1}$ becomes vertical; therefore,

$$
\begin{aligned}
& \psi_{f}=\pi / 2, \\
& \sigma_{z}=q_{f}=p_{f}+R_{f} .
\end{aligned}
$$

As shown in Figure 1C, the stress characteristic network includes 3 zones: OAB, OCD, and OBC zones. The solution starts from the known state of stress along the boundary OD. This boundary is divided into $n_{1}$ number of points, and the coordinates $r$ and $z$ of each point are calculated. The values of $\psi_{0}$ for all these points are 0 , and the values of $p_{0}$ are then calculated from Equation 16. From the known state of stress along the line OD, the state of stress and the characteristic pattern in the zones $\mathrm{OBC}$ and OCD are then calculated by using the finite difference technique.

Note that at point $\mathrm{O}$, there remains a stress singularity since the state of stress remains different on its left and right sides. At this point, $\mathrm{d} r=\mathrm{d} z=0$, and Equation 10 changes to

$$
-\sin 2 \mu \mathrm{d} p+2 R \mathrm{~d} \psi=0 .
$$

To deal with this stress singularity, a very small zone around the converging stress characteristics at this point is divided into $n_{\mathrm{g}}$ number of divisions. To find the value of $p$ at each point, the finite difference form of Equation 18 is used.

By integrating the vertical normal stress along the footing base OA, the ultimate bearing capacity $q_{\mathrm{u}}$ is computed as follows:

- Strip footing:

$$
q_{\mathrm{u}}=\frac{1}{b} \int_{\mathrm{OA}} \sigma_{\mathrm{z}} \mathrm{d} r
$$

- Circular footing:

$$
q_{\mathrm{u}}=\frac{2}{b^{2}} \int_{\mathrm{OA}} \sigma_{z} r \mathrm{~d} r
$$

\section{2 | Rough footing}

For a rough footing, the major principal stress at $r=z=0$ must be vertical along the footing base $(\psi=\pi / 2)$. If the full roughness is mobilized at any point, then the converging characteristics need to be tangential to the footing base, ${ }^{13,14}$ $\psi_{f}=\pi-\mu_{f}$. 


$$
\psi_{f}=\pi-0.5 \cos ^{-1}\left(\frac{1}{\left\{1+(1-a)\left(\frac{R_{f}}{\beta_{a}}\right)^{k}(1+k)\right\}}\right)
$$

Figure 1D illustrates the stress characteristic patterns for a rough footing. Along the stress characteristic OB, which becomes the boundary of the nonplastic zone below the footing, the direction of the major principal stress becomes vertical. The solution procedure becomes similar to that for a smooth footing, but the slip line patterns involve only 2 zones, namely, OCD and OBC; the region OBC is often termed as the radial shear zone. For a chosen value of $b$, the values of $\psi$ at the right side of point $\mathrm{O}$ and $L_{2}$ should be obtained such that at point $\mathrm{B}, r=0$ and $\psi=\pi / 2$. A trial and iterative procedure is used for doing the necessary computations to establish the state of stress everywhere along the characteristic OB.

TABLE 1 The variation of $N_{\sigma}$ with the number of divisions for different combinations of $G S I, m_{i}$, and $\sigma_{\mathrm{c}} /(\gamma b)\left(n_{g}=n_{1}\right)$ for $q / \sigma_{\mathrm{c}}=0$ and $D=0$

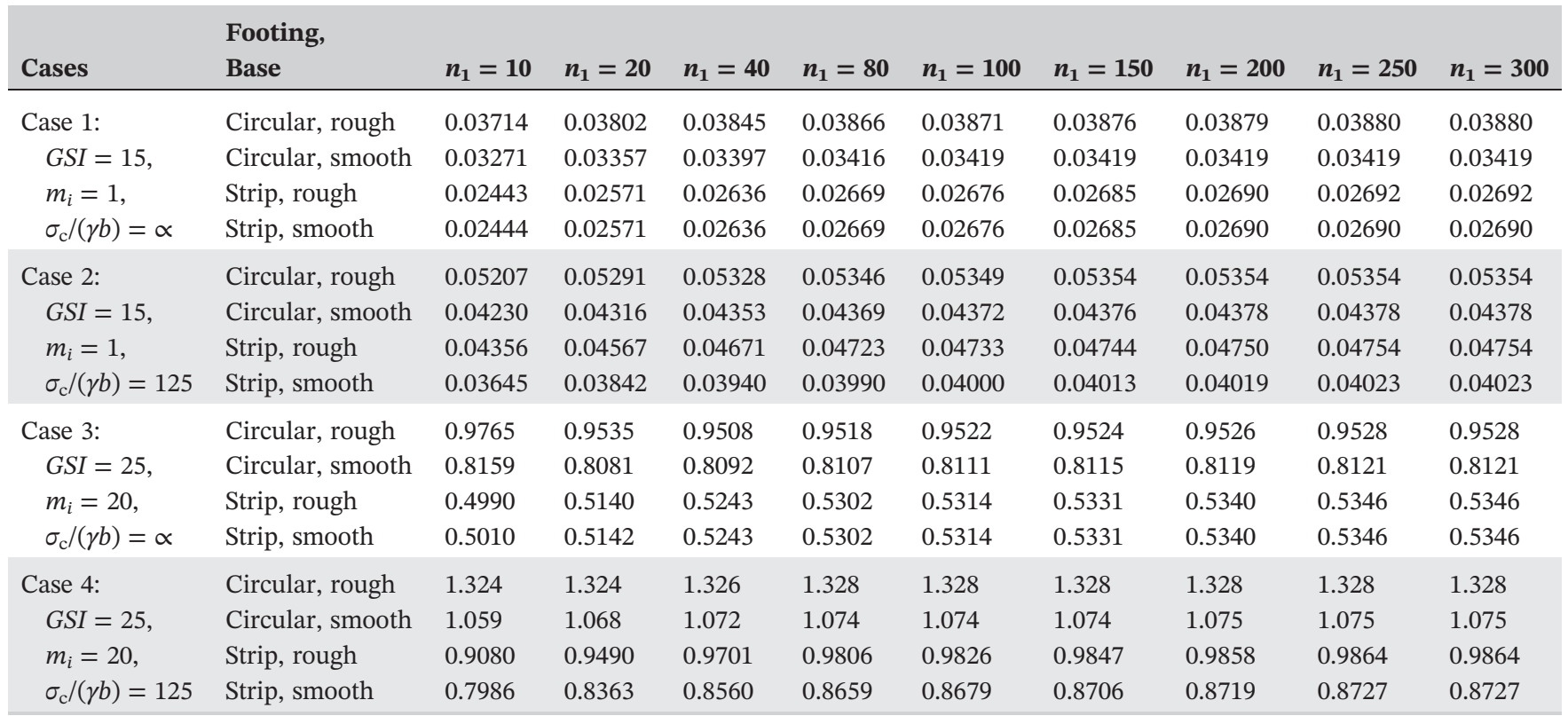

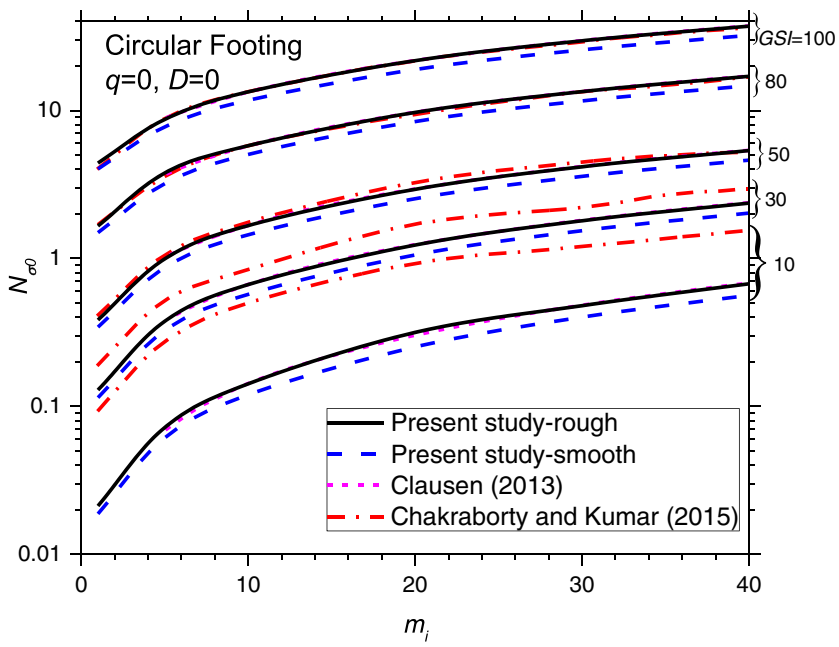

FIGURE 2 The variation of $N_{\sigma 0}$ with $m_{i}$ and GSI for smooth and rough circular footing and comparison with the existing results for a rough base [Colour figure can be viewed at wileyonlinelibrary.com] 
The ultimate bearing capacity $q_{\mathrm{u}}$ for the rough footing is calculated by using the approach similar to that of $\operatorname{Kumar}^{13}$ by integrating the stress components along the OB:

- For a strip footing:

$$
q_{\mathrm{u}}=\frac{1}{b} \int_{\text {ОВ }}\left\{\sigma_{z} \mathrm{~d} r+\gamma z \mathrm{~d} r+\tau_{r z} \mathrm{~d} z\right\}
$$
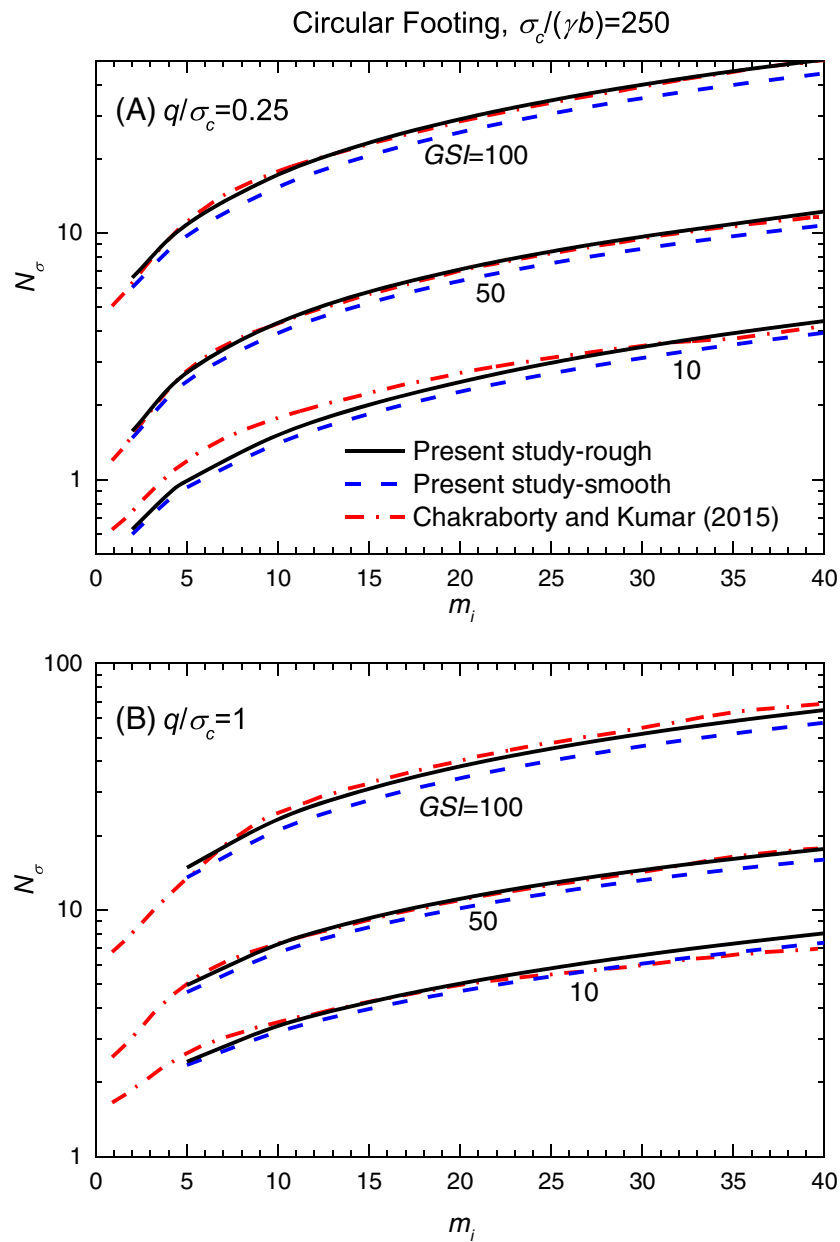

FIGURE 3 The variation of $N_{\sigma}$ with $m_{i}$ and GSI for smooth and rough circular footing and comparison with the existing results for a rough base. A, $q / \sigma_{\mathrm{c}}=0.25 . \mathrm{B}, q / \sigma_{\mathrm{c}}=1$ [Colour figure can be viewed at wileyonlinelibrary.com]

TABLE 2 The variation of $N_{\sigma}$ with $G S I, \sigma_{\mathrm{c}} /(\gamma b)$, and $m_{i}$ for a circular footing with smooth and rough base and its comparison with the results of Clausen ${ }^{6}$ for a rough base

\begin{tabular}{lccccc} 
GSI & $\sigma_{\mathrm{c}} /(\mathbf{2} \boldsymbol{\gamma} \mathbf{b})$ & $\boldsymbol{m}_{\boldsymbol{i}}$ & $\boldsymbol{N}_{\sigma}$, Clausen $^{\mathbf{6}}$ & $\boldsymbol{N}_{\sigma}$, This Study, Smooth & $\boldsymbol{N}_{\sigma}$, This Study, Rough \\
\hline 10 & 125 & 7.5 & 0.176 & 0.137 & 0.174 \\
20 & 2000 & 22.5 & 0.851 & 0.707 & 0.846 \\
30 & $\infty$ & 22.5 & 1.381 & 1.176 & 1.351 \\
\hline 40 & 250 & 35 & 3.544 & 2.963 & 3.519 \\
\hline 50 & 5000 & 10 & 1.678 & 1.446 & 1.661 \\
60 & $\infty$ & 35 & 7.053 & 6.053 & 6.940 \\
80 & 500 & 10 & 5.818 & 5.049 & 5.788 \\
100 & 250 & 22.5 & 23.91 & 20.664 & 23.787 \\
\hline
\end{tabular}


TABLE 3 The variation of $N_{\sigma 0}$ with $G S I, \sigma_{\mathrm{c}} /(\gamma b)$, and $m_{i}$ for a strip footing with smooth and rough bases and comparison with the results of Merifield et $\mathrm{al}^{4}$ and Chakraborty and $\mathrm{Kumar}^{7}$ with a rough base

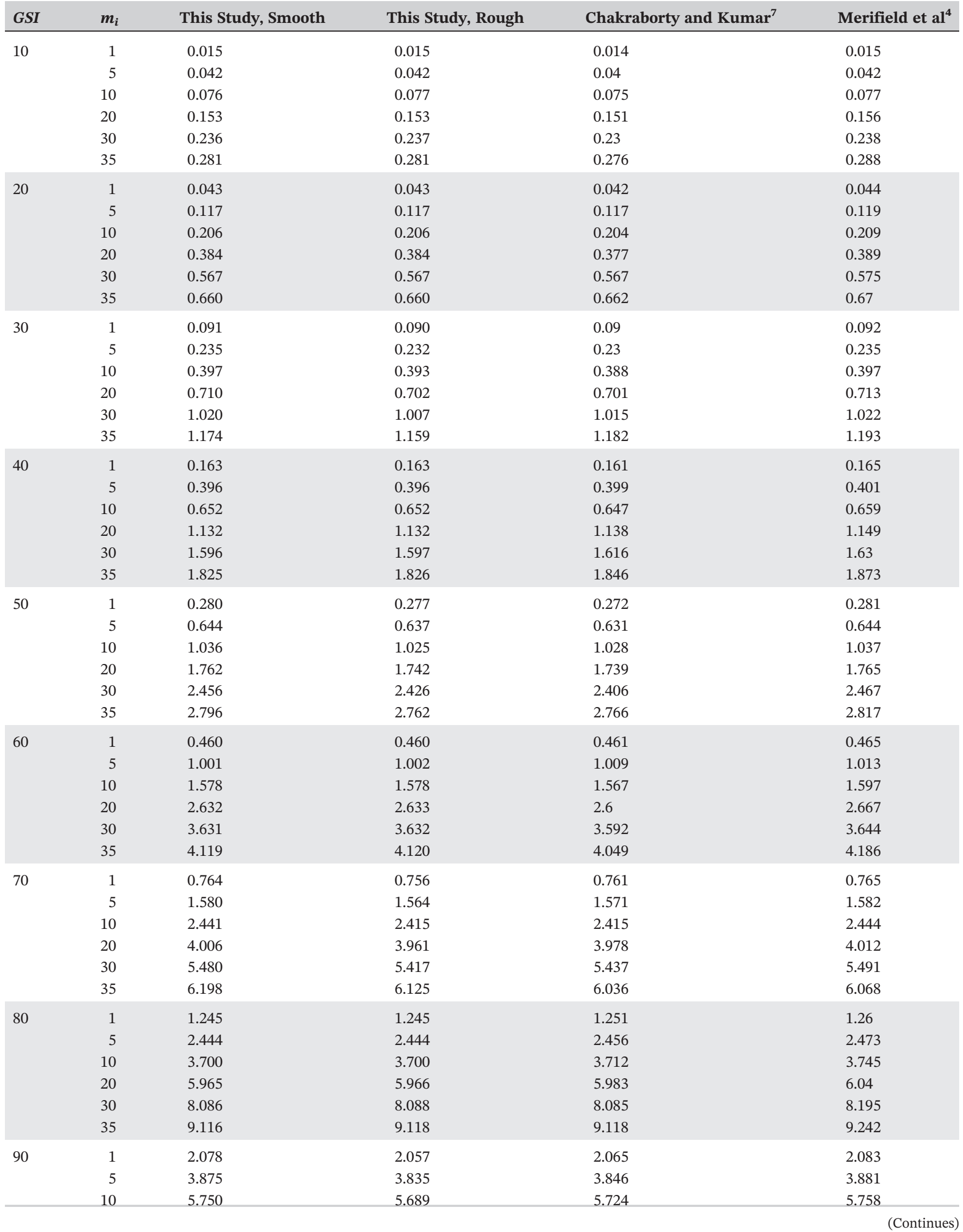


TABLE 3 (Continued)

\begin{tabular}{|c|c|c|c|c|c|}
\hline GSI & $m_{i}$ & This Study, Smooth & This Study, Rough & Chakraborty and Kumar ${ }^{7}$ & Merifield et $\mathrm{al}^{4}$ \\
\hline & 20 & 9.114 & 9.015 & 9.086 & 9.125 \\
\hline & 30 & 12.251 & 12.114 & 12.198 & 12.27 \\
\hline \multirow[t]{4}{*}{100} & 1 & 3.416 & 3.416 & 3.433 & 3.461 \\
\hline & 5 & 6.049 & 6.050 & 6.095 & 6.124 \\
\hline & 30 & 18.213 & 18.217 & 18.398 & 18.444 \\
\hline & 35 & 20.404 & 20.409 & 20.587 & 20.668 \\
\hline
\end{tabular}

- For a circular footing:

$$
q_{\mathrm{u}}=\frac{1}{\pi b^{2}} \int_{\mathrm{OB}}\left\{\sigma_{z}(2 \pi r) \mathrm{d} r+\gamma z(2 \pi r) \mathrm{d} r+\tau_{r z}(2 \pi r) \mathrm{d} z\right\}
$$

\section{5 | DEFINITION OF BEARING CAPACITY FACTORS}

The ultimate bearing capacity $\left(q_{\mathrm{u}}\right)$ is expressed in terms of a nondimensional bearing capacity factor $N_{\sigma}$ as given herein:

$$
q_{\mathrm{u}}=\sigma_{\mathrm{c}} N_{\sigma}
$$
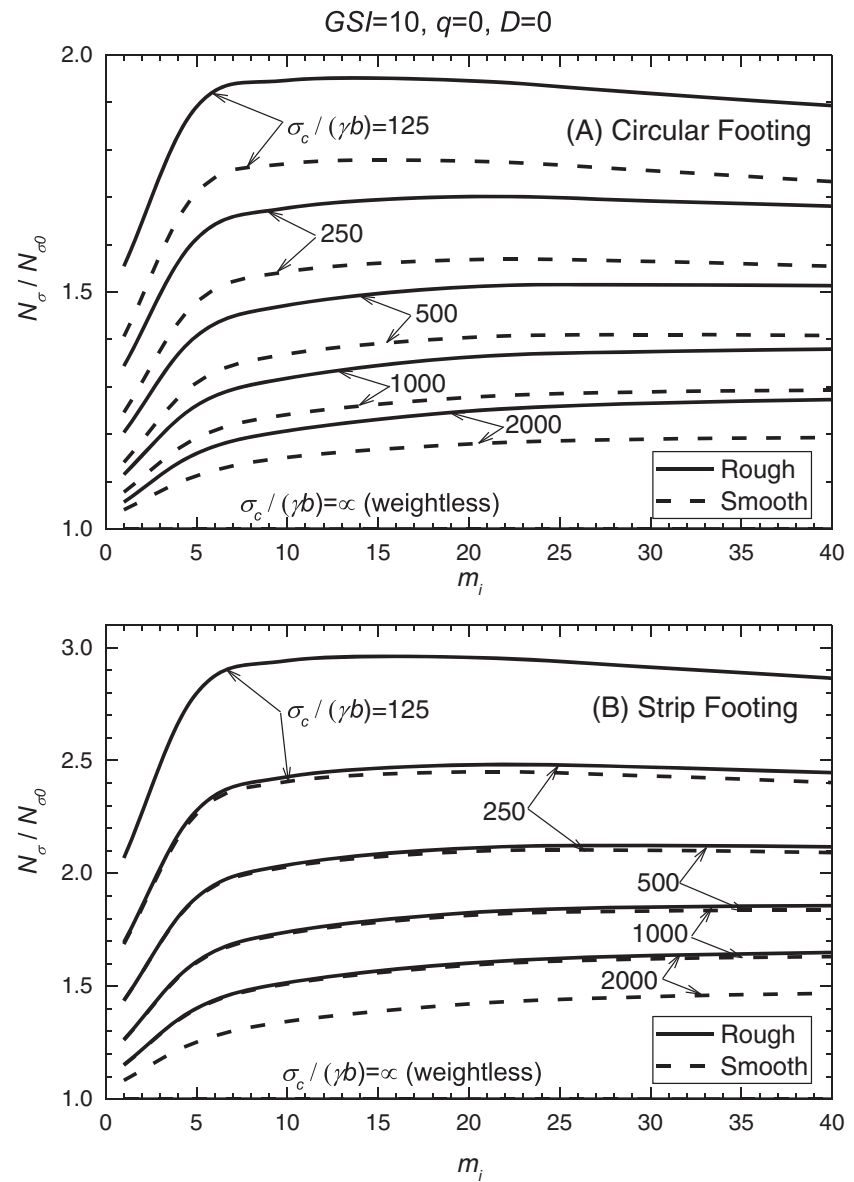

FIGURE 4 The variation of $N_{\sigma} / N_{\sigma 0}$ with $m_{i}$ and $\sigma_{\mathrm{c}} /(\gamma b)$ for $G S I=10, q=0$, and $D=0$ with smooth and rough bases for (A) circular footing and (B) strip footing 
where $N_{\sigma}$ is a nondimensional bearing capacity factor, which is simply termed as $N_{\sigma 0}$ for a weightless rock mass $(\gamma=0)$.

\section{6 | RESULTS}

\section{1 | Convergence check}

It is understood from the work of Martin ${ }^{15}$ that the accuracy of the obtained solution can be increased by using a large number of characteristics along the ground surface and at the footing edge (singular point). This can be done by increasing the values of the input parameters $n_{1}$ and $n_{g}$ as defined earlier; note that $n_{1}$ provides the number of divisions along the ground surface and $n_{g}$ refers to the number of divisions kept to model the singular point. The values of $n_{1}$ and $n_{g}$ were increased till the value of the bearing capacity factor becomes more or less constant up to the fourth significant digit. To illustrate the convergence of the obtained solution, the values of the bearing capacity factor were determined for the following 4 cases by keeping $q / \sigma_{\mathrm{c}}=0$ and $D=0$ : (1) case $1, G S I=15, m_{i}=1$, and $\sigma_{\mathrm{c}} /(\gamma b)=\propto$; (2) case $2, G S I=15, m_{i}=1$, and $\sigma_{\mathrm{c}} /(\gamma b)=125$; (3) case 3, GSI $=25, m_{i}=20$, and $\sigma_{\mathrm{c}} /(\gamma b)=\alpha$; and (4) case 4: $G S I=25, m_{i}=20$, and $\sigma_{\mathrm{c}} /(\gamma b)=125$. The results corresponding to these 4 cases are presented in Table 1 for both smooth and rough footing bases; the results in all the cases were provided in terms of 4 significant digits. The value of $n_{g}$ was kept equal to that of $n_{1}$. Calculations were conducted by increasing the value of $n_{1}$ from 10 to 300. It can be observed that for most cases, the optimum value of $n_{1}$ becomes equal to 250 . Note that for a weightless rock mass, $\sigma_{\mathcal{C}} /(\gamma b)=\propto$, the bearing capacity of smooth and rough strip footings becomes almost the same. However, when the weight of the rock mass is considered, the bearing capacity of a rough footing becomes greater than that for a smooth footing.
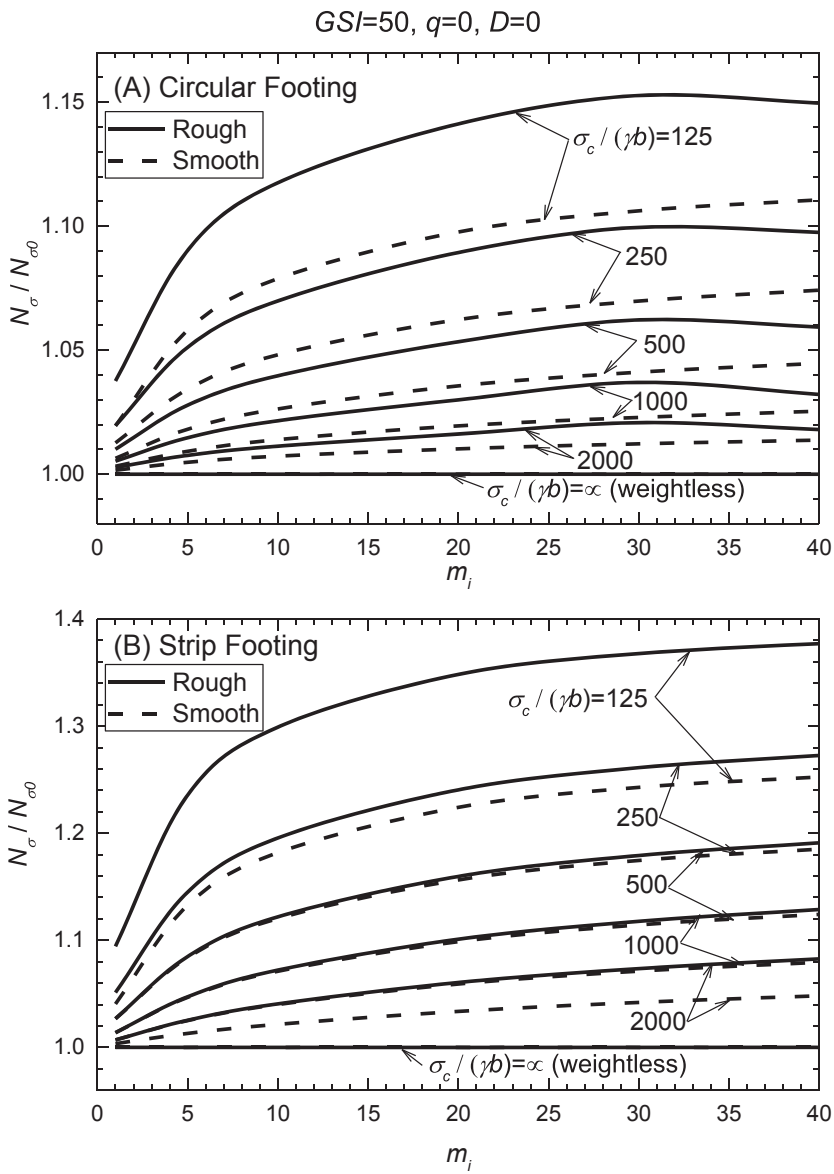

FIGURE 5 The variation of $N_{\sigma} / N_{\sigma 0}$ with $m_{i}$ and $\sigma_{\mathrm{c}} /(\gamma b)$ for $G S I=50, q=0$, and $D=0$ with smooth and rough bases for (A) circular footing and (B) strip footing 


\section{2 | Variation of the bearing capacity factors}

Figure 2 presents the values of $N_{\sigma 0}$ obtained from the present study for both smooth and rough circular footings. The values of $N_{\sigma 0}$ for a smooth footing for all the values of GSI become smaller than those for a rough footing. The maximum difference between the values of $N_{\sigma 0}$ for smooth and rough footings is found to be around $25 \%$. The factor $N_{\sigma 0}$ increases continuously with an increase in the values of $m_{i}$ and GSI. In this figure, a comparison of the results from the present analysis has also been made with that reported by (1) Clausen ${ }^{6}$ on the basis of an elastoplastic finite element method for a rough footing and (2) Chakraborty and $\mathrm{Kumar}^{7}$ by using the lower-bound finite element limit analysis for a rough footing but with an assumption $a=0.5$. Note that the present results are found to be almost the same as that reported by Clausen. ${ }^{6}$ The analysis of Chakraborty and $\mathrm{Kumar}^{7}$ overestimates the values of $N_{\sigma 0}$, especially for values of $G S I<50$. It can be noted from Equation 2 that when the value of GSI increases from 10 to 100, the magnitude of the exponent $a$ reduces from 0.58 to 0.5 . Therefore, as the GSI reduces, especially below 50, the difference between the present results and that given by Chakraborty and Kumar ${ }^{7}$ is found to become quite extensive. Similar observations with reference to the effect of exponent $a$ on the results have been indicated by Clausen ${ }^{16}$ while discussing the results of Chakraborty and Kumar. ${ }^{7}$

Figure 3 provides the variation of the factor $N_{\sigma}$ with $m_{i}$ for different values of GSI for a circular footing for 2 different values of $q / \sigma_{c}$, namely, 0.25 and 1 . Similar to $N_{\sigma 0}$, the factor $N_{\sigma}$ increases with an increase in the values of $G S I$ and $m_{i}$. For a rough footing, the factor $N_{\sigma}$ becomes greater than the corresponding values for a smooth footing. Figure 3 also provides a comparison between the present results and that computed by Chakraborty and Kumar. ${ }^{7}$ It can be seen that for values of $G S I \geq 50$, the results from the present study become very close to the solution given by Chakraborty and Kumar. ${ }^{7}$ For different values of $G S I, \sigma_{\mathrm{c}} /(2 \gamma b)$, and $m_{i}$, a comparison between the present values of $N_{\sigma}$ and that given by Clausen ${ }^{6}$ for a rough circular footing is presented in Table 2 . The present results become very close to that given by Clausen. ${ }^{6}$ The maximum difference between the 2 solutions has been found to be $2.2 \%$.

For a strip footing, the bearing capacity factor $N_{\sigma 0}$ for a weightless rock mass has been presented in Table 3 for different values of GSI and $m_{i}$. For a strip footing, the roughness of the footing hardly affects the values of $N_{\sigma 0}$. This table also shows a comparison between the present values for $N_{\sigma 0}$ and those reported by (1) Merifield et $\mathrm{al}^{4}$ and (2)
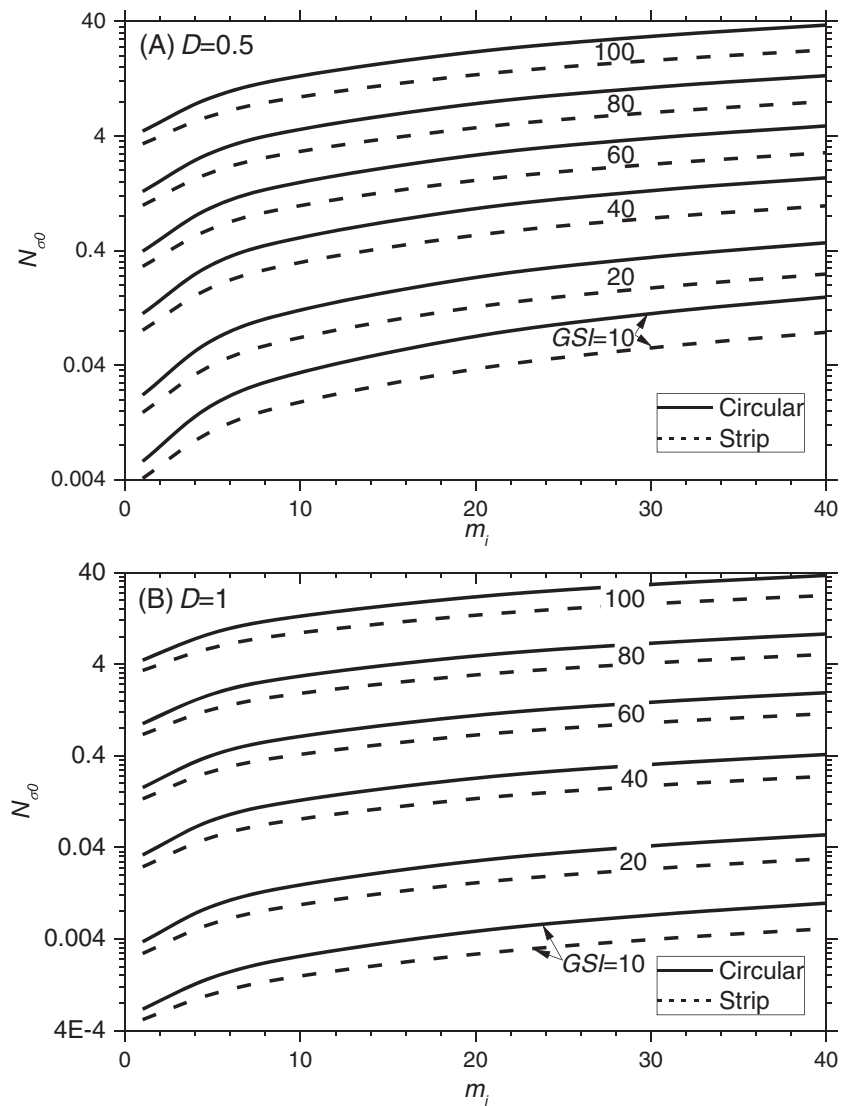

FIGURE 6 The variation of $N_{\sigma 0}$ with $m_{i}$ and $G S I$ for rough circular and strip footings for (A) $D=0.5$ and (B) $D=1$ 
Chakraborty and Kumar. ${ }^{7}$ Note that the present results remain very close to the solutions of Merifield et $\mathrm{al}^{4}$ and Chakraborty and Kumar. ${ }^{7}$

To evaluate the effect of the rock mass unit weight on the ultimate bearing capacity, Figures 4 and 5 have been drawn for the variation of $N_{\sigma} / N_{\sigma 0}$ with $m_{i}$ corresponding to different values of $\sigma_{\mathrm{c}} /(\gamma b)$ with 2 different magnitudes of $G S I$, namely, 10 and 50. Note that the ratio $N_{\sigma} / N_{\sigma 0}$ decreases continuously with an increase in the value of $\sigma_{\mathrm{c}} /(\gamma b)$. For a weightless rock mass, $\sigma_{\mathrm{c}} /(\gamma b)=\infty$, the magnitude of $N_{\sigma}$ becomes simply equal to $N_{\sigma 0}$. The factor $N_{\sigma} / N_{\sigma 0}$ for a strip footing is found to be greater than that for a circular footing corresponding to the same values of $\sigma_{\mathrm{c}} /(\gamma b), G S I, m_{i}$, and $q / \sigma_{\mathrm{c}}$. Furthermore, the rock mass unit weight has been found to have more effect for smaller values of $\sigma_{\mathrm{c}} /(\gamma b), G S I, m_{i}$, and $q / \sigma_{\mathrm{c}}$.

Figure 6 presents the influence of the disturbance factor $D$ on the factor $N_{\sigma 0}$ for rough circular and strip footings. It can be seen that the factor $N_{\sigma 0}$ decreases with an increase in the value of $D$.

\section{3 | Pressure distribution below the footing base}

For $\sigma_{\mathrm{c}} /(\gamma b)=250$, Figure 7A,B illustrates the normalized pressure distribution $\left(q / \sigma_{\mathrm{c}}\right)$ below the footing base for different values of $m_{i}$ corresponding to circular and strip footing, respectively. Note that as compared with a smooth footing, the magnitude of the pressure becomes greater for a rough footing. It can be seen that the pressure distribution below the footing base does not become either uniform or linear. The maximum value of $q_{f}$, in all the cases, has been found to occur at the center of the circular footing. Around the center of the footing, the shape of the pressure distribution tends to become concave and convex, corresponding to circular and strip footings, respectively. Note that as compared with a strip footing, the magnitude of the normalized pressure becomes greater for a circular footing. Figure 8 also shows the pressure distribution below the footing base for smooth and rough strip and circular footings but for different values of $\sigma_{\mathrm{c}} /(\gamma b)$. It can be seen that the magnitude of the pressure decreases continuously with an increase in the value of $\sigma_{\mathrm{c}} /(\gamma b)$. Note that for the strip footing, the difference between the values of pressure of the smooth and rough footings
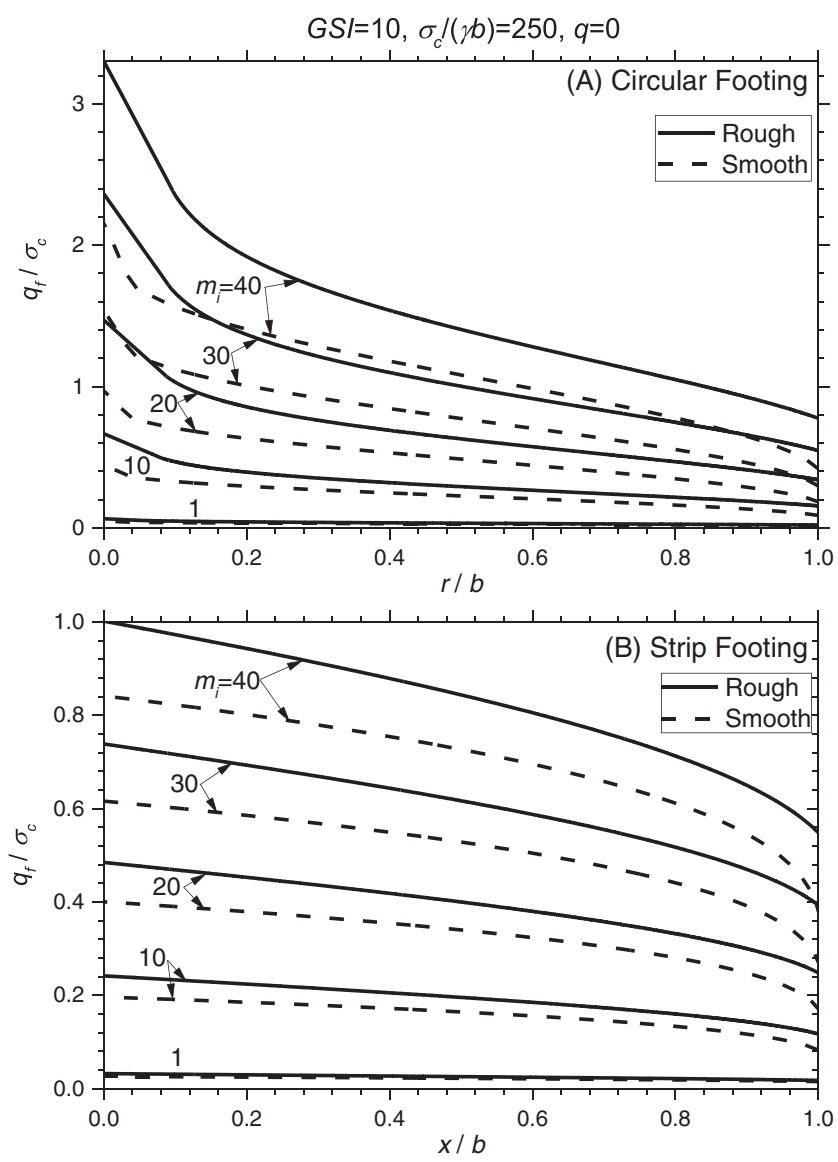

FIGURE 7 The pressure distribution below the footing base for different values of $m_{i}$ with $G S I=10$ and $\sigma_{\mathrm{c}} /(\gamma b)=250$ for $(\mathrm{A})$ circular footing and (B) strip footing 

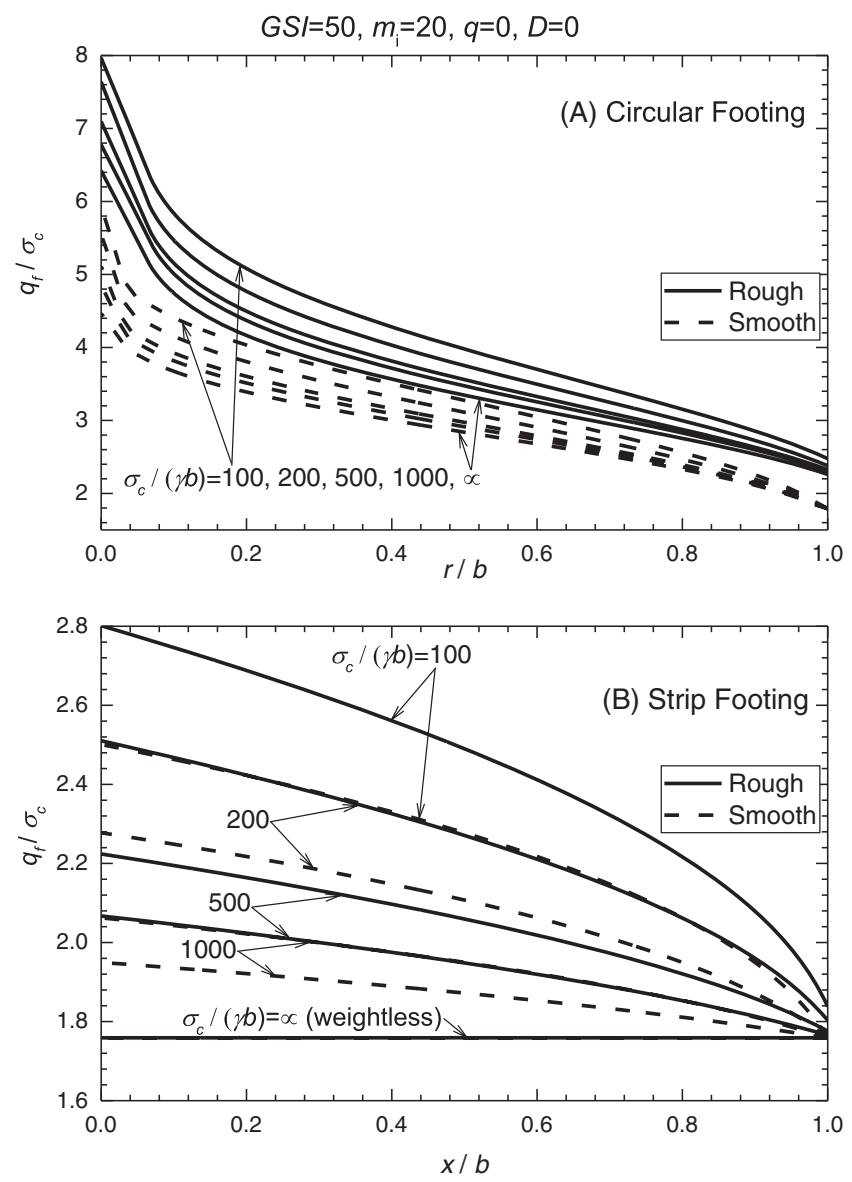

FIGURE 8 The pressure distribution below the footing base for different values of $\sigma_{\mathrm{c}} /(\gamma b)$ with $G S I=50$ and $m_{i}=20$ for (A) circular footing and (B) strip footing

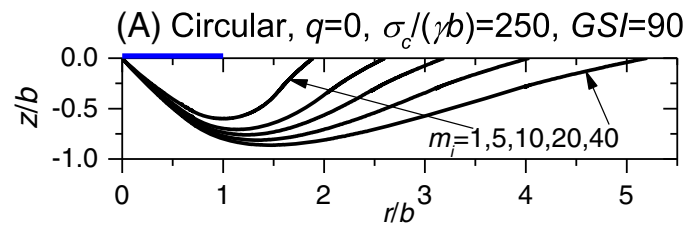

(B) Circular, $\sigma_{c} /(\gamma b)=250, G S I=50, m_{i}=20$

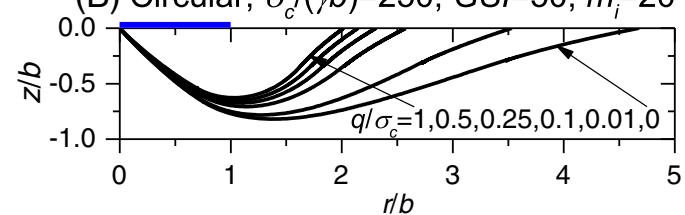

(C) Circular, $q=0, G S I=60, m_{i}=5$

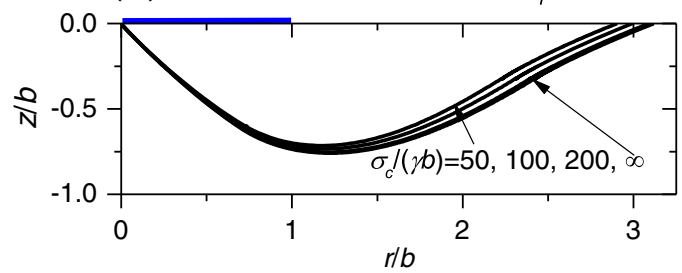

(D) Strip, $q=0, \sigma_{c} /(\gamma b)=250, G S I=90$

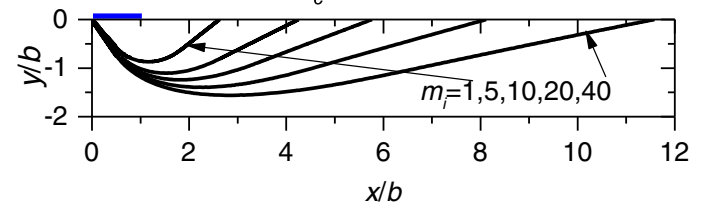

(E) Strip, $\sigma_{c} /(\gamma b)=250, G S I=50, m_{i}=20$

(F) Strip, $q=0, G S I=60, m_{i}=5$
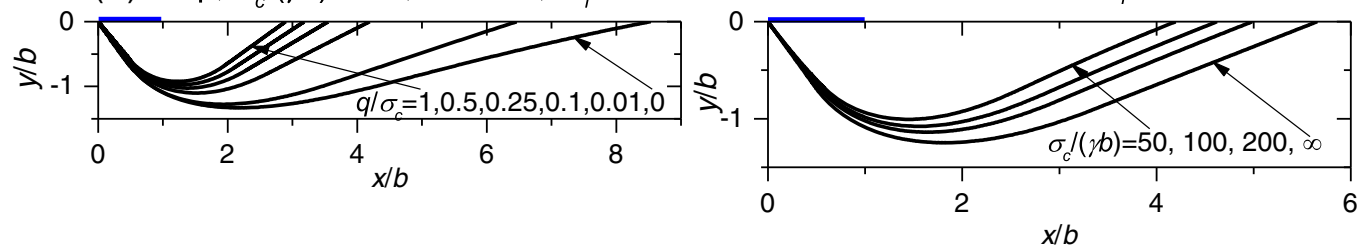

FIGURE 9 The effect of $m_{i}, q / \sigma_{\mathrm{c}}$, and $\sigma_{\mathrm{c}} /(\gamma b)$ on the failure patterns for circular and strip footings with smooth base [Colour figure can be viewed at wileyonlinelibrary.com] 
(A) Circular, $q=0, \sigma_{c} /(\gamma b)=250, G S I=90$

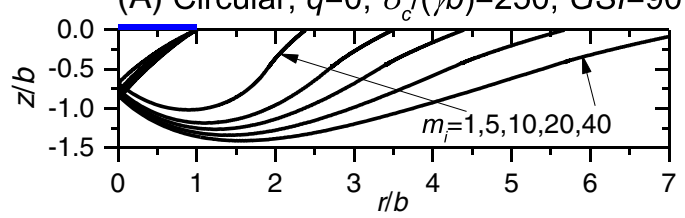

(C) Circular, $q=0, G S I=60, m_{i}=5$

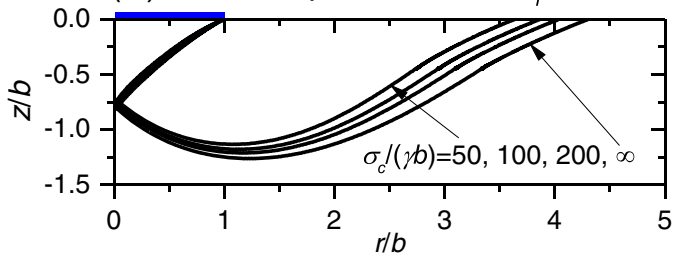

(E) Strip, $\sigma_{c} /(\gamma b)=250, G S /=50, m_{i}=20$

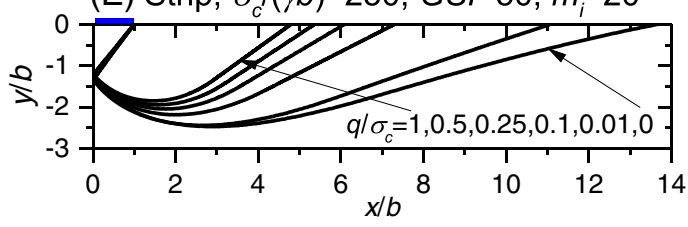

(B) Circular, $\sigma_{c} /(\gamma b)=250, G S /=50, m_{i}=20$

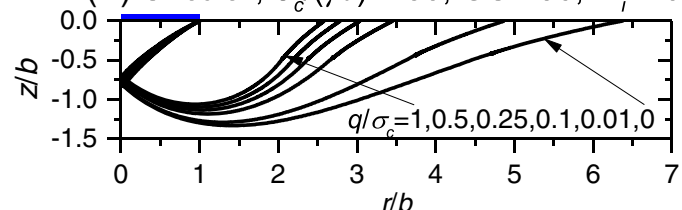

(D) Strip, $q=0, \sigma_{c} /(\not b)=250, G S /=90$

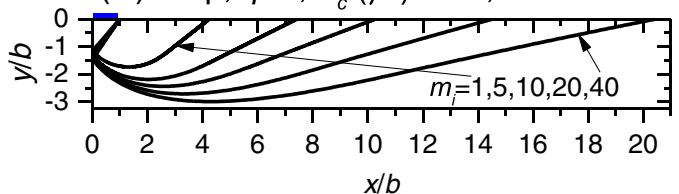

(F) Strip, $q=0, G S I=60, m_{i}=5$

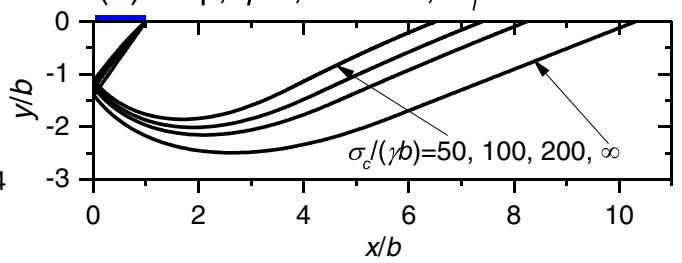

FIGURE 10 The effects of $m_{i}, q / \sigma_{\mathrm{c}}$, and $\sigma_{\mathrm{c}} /(\gamma b)$ on the failure patterns for circular and strip footings with rough base [Colour figure can be viewed at wileyonlinelibrary.com]

(A) Circular, GSI=90, $m_{i}=1, q / \sigma_{\mathrm{c}}=0, \sigma_{\mathrm{c}} /(\gamma b)=250$

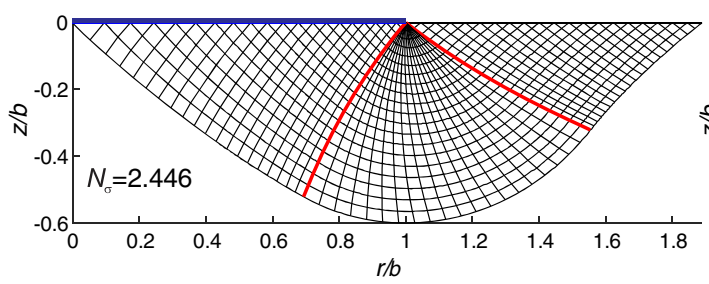

(C) Circular, GSI=60, $m_{i}=5, q / \sigma_{\mathrm{c}}=0, \sigma_{\mathrm{c}} /(\gamma b)=50$

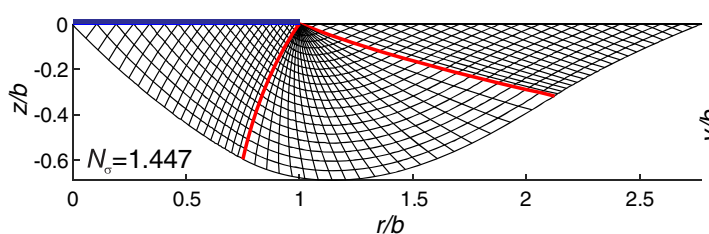

(E) Strip, GSI=50, $m_{i}=20, q / \sigma_{\mathrm{c}}=1, \sigma_{\mathrm{c}}(\gamma b)=250$

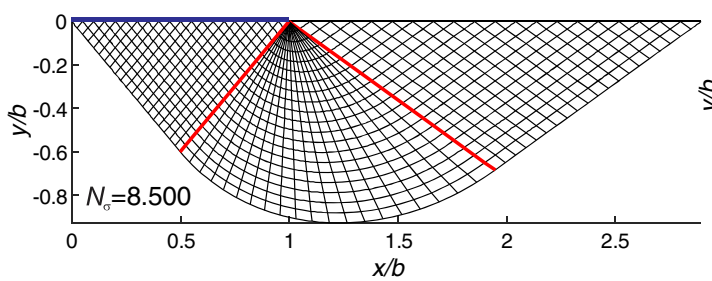

(B) Circular, GSI $=50, m_{i}=20, q / \sigma_{\mathrm{c}}=1, \sigma_{\mathrm{c}} /(\gamma b)=250$

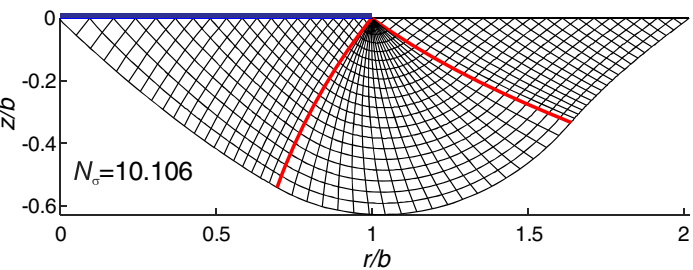

(D) Strip, GSI=90, $m_{i}=1, q / \sigma_{\mathrm{c}}=0, \sigma_{\mathrm{c}} /(\gamma b)=250$

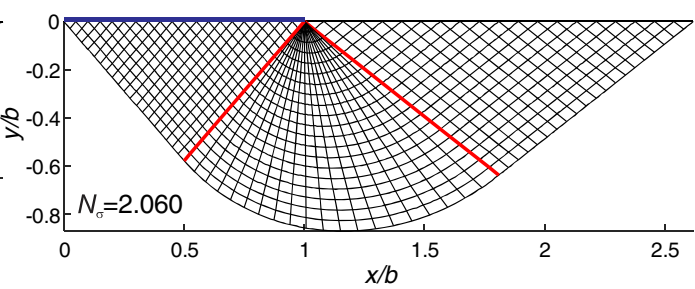

(F) Strip, $G S I=60, m_{i}=5, q / \sigma_{\mathrm{c}}=0, \sigma_{\mathrm{c}} /(\gamma b)=50$

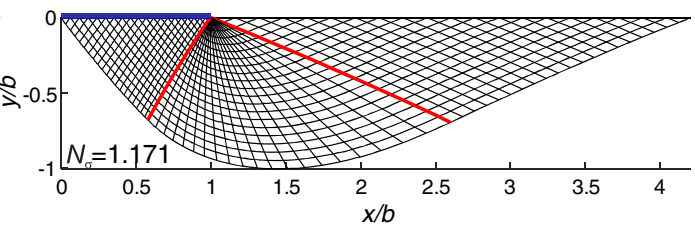

FIGURE 11 Complete slip patterns for circular and strip footings with smooth base [Colour figure can be viewed at wileyonlinelibrary. com] 
(A) Circular, GSI=90, $m_{i}=1, q / \sigma_{\mathrm{c}}=0, \sigma_{\mathrm{c}} /(\gamma b)=250$

(B) Circular, GSI=50, $m_{i}=20, q / \sigma_{\mathrm{c}}=1, \sigma_{\mathrm{c}} /(\gamma b)=250$
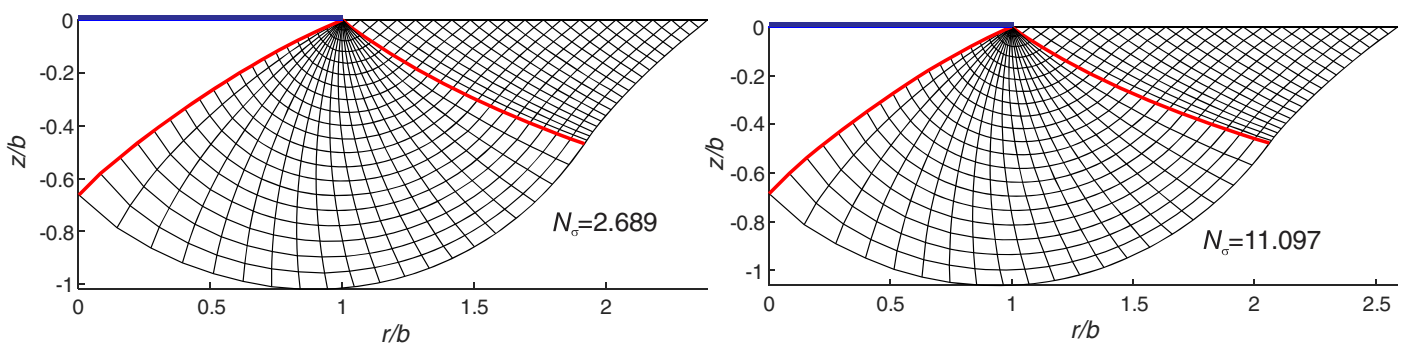

(C) Circular, GSI $=60, m_{i}=5, q / \sigma_{\mathrm{c}}=0, \sigma_{\mathrm{c}} /(\gamma b)=50$

(D) Strip, $G S I=90, m_{i}=1, q / \sigma_{\mathrm{c}}=0, \sigma_{\mathrm{c}} /(\gamma b)=250$
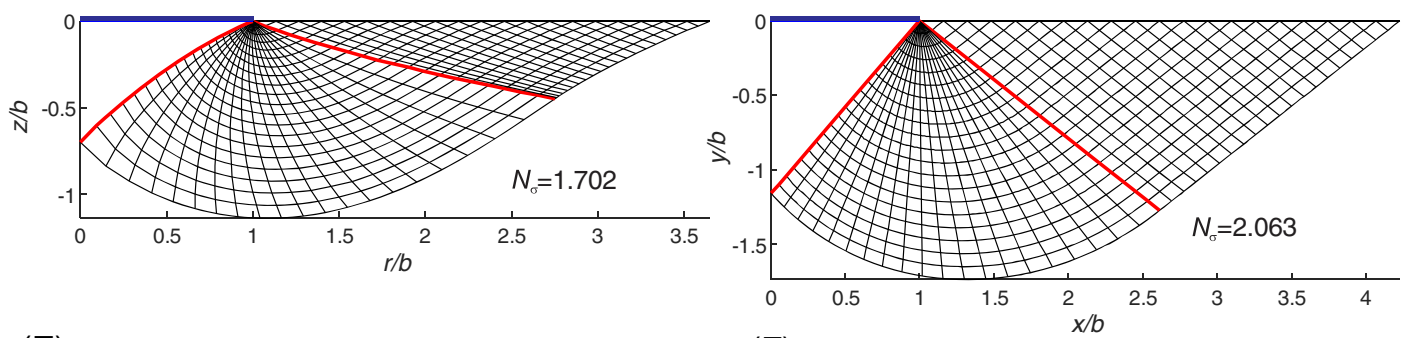

(E) Strip, $G S /=50, m_{i}=20, q / \sigma_{c}=1, \sigma_{c}(\gamma b)=250$

(F) Strip, $G S I=60, m_{i}=5, q / \sigma_{c}=0, \sigma_{c} /(\gamma b)=50$
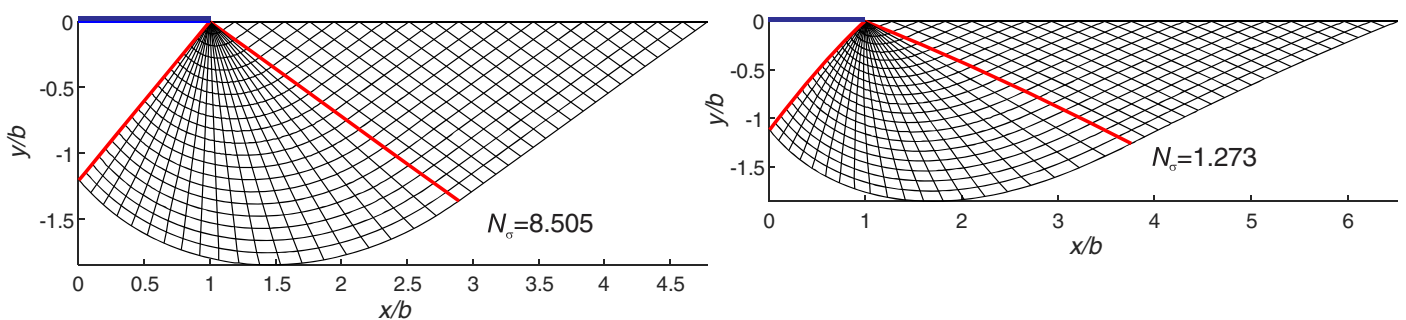

FIGURE 12 Complete slip patterns for circular and strip footings with rough base [Colour figure can be viewed at wileyonlinelibrary.com]

decreases with an increase in $\sigma_{\mathrm{c}} /(\gamma b)$ and for the weightless rock mass, the pressure distributions of the smooth and rough strip footings are almost the same.

\section{4 | Failure patterns}

One of the significant advantages of the method of stress characteristics is that the failure patterns are automatically generated as a part of the solution during the process of computing the state of stress everywhere within the plastic domain. The effects of the different input parameters, namely, $\sigma_{\mathrm{c}} /(\gamma b), m_{i}$, and $q / \sigma_{\mathrm{c}}$, on the slip line patterns are shown in Figures 9 and 10 for smooth and rough footings, respectively; the parts A to $\mathrm{C}$ present the slip line patterns for a circular footing, and the parts D to F show the corresponding patterns for a strip footing. These two figures are also redrawn in Figures 11 and 12 to provide the complete fan of slip patterns for a few typical cases. The selected input parameters for each case are indicated in these figures. It can be observed that with an increase in $m_{i}$, the size of the plastic zone extends continuously, and accordingly, the extent of the failure surface at the ground surface also increases. The effect of $\sigma_{\mathrm{c}} /(\gamma b)$ on the slip line patterns was noted to be similar to that of $m_{i}$. However, the parameter $q / \sigma_{\mathrm{c}}$ was found to have a reverse effect on the slip line patterns (Figure 9B,E). For the same parameters, the extent of the failure surface for a rough footing is found to be greater than that for a smooth footing. In terms of normalized axes, a strip footing provides more extension of the slip line patterns as compared with the corresponding circular footing with the same input parameters.

\section{7 | CONCLUSIONS}

The ultimate bearing capacity of circular and strip footings, placed over rock mass, has been numerically evaluated by using the method of stress characteristics for both smooth and rough footing-rock interface. The modified HB failure 
criterion, which is the widely accepted yield basis to characterize the rock mass, was used in the analysis. Various steps have been provided in detail for describing the procedure. The bearing capacity has been presented in the form of nondimensional bearing capacity factors as a function of different input parameters for rock mass. It has been clearly noted that an increase of GSI and $m_{i}$ leads to an increase in the values of $N_{\sigma}$ and $N_{\sigma 0}$. An increase in the surcharge pressure causes a further increase in the values of both $N_{\sigma}$ and $N_{\sigma 0}$. The factor $N_{\sigma}$ has been found to increase continuously with a decrease in the value of $\sigma_{\mathrm{c}} /(\gamma b)$. The roughness of the footing has been found to have more significant effect for a circular footing as compared with a strip footing. The results obtained from the present study have been found to compare quite well with the different solutions available from literature.

\section{ORCID}

Amin Keshavarz @ http://orcid.org/0000-0002-8951-9233

Jyant Kumar (1) http://orcid.org/0000-0002-7808-8984

\section{REFERENCES}

1. Serrano A, Olalla C. Ultimate bearing capacity of rock masses. Int J Rock Mech Min Sci. 1994;31(2):93-106. https://doi.org/10.1016/01489062(94)92799-5

2. Serrano A, Olalla C, Gonzalez J. Ultimate bearing capacity of rock masses based on the modified Hoek-Brown criterion. Int J Rock Mech Min Sci. 2000;37(6):1013-1018. https://doi.org/10.1016/S1365-1609(00)00028-9

3. Yang X, Yin JH, Li L. Influence of a nonlinear failure criterion on the bearing capacity of a strip footing resting on rock mass using a lower bound approach. Canadian Geotechnical Journal. 2003;40(3):702-707. https://doi.org/10.1139/t03-010

4. Merifield R, Lyamin A, Sloan S. Limit analysis solutions for the bearing capacity of rock masses using the generalised Hoek-Brown criterion. Int J Rock Mech Min Sci. 2006;43(6):920-937. https://doi.org/10.1016/j.ijrmms.2006.02.001

5. Zhou XP, Yang HQ, Zhang YX, Yu MH. The effect of the intermediate principal stress on the ultimate bearing capacity of a foundation on rock masses. Computers and Geotechnics. 2009;36(5):861-870. https://doi.org/10.1016/j.compgeo.2009.01.009

6. Clausen J. Bearing capacity of circular footings on a Hoek-Brown material. Int J Rock Mech Min Sci. 2013;57:34-41. https://doi.org/10.1016/ j.ijrmms.2012.08.004

7. Chakraborty M, Kumar J. Bearing capacity of circular footings over rock mass by using axisymmetric quasi lower bound finite element limit analysis. Computers and Geotechnics. 2015;70:138-149. https://doi.org/10.1016/j.compgeo.2015.07.015

8. Keshavarz A, Fazeli A, Sadeghi S. Seismic bearing capacity of strip footings on rock masses using the Hoek-Brown failure criterion. J Rock Mech Geotech Eng. 2016;8(2):170-177. https://doi.org/10.1016/j.jrmge.2015.10.003

9. Hoek E, Wood D, Shah S. A modified Hoek-Brown criterion for jointed rock masses. in Proc. Rock Characterization, Symp. Int. Soc. Rock Mech.: Eurock. 1992.

10. Hoek E, Carranza-Torres C, Corkum B. Hoek-Brown failure criterion-2002 edition. in Proceedings of NARMS-Tac. 2002.

11. Booker J, Davis E. A general treatment of plastic anisotropy under conditions of plane strain. J Mech Phys Solids. 1972;20(4):239-250. https://doi.org/10.1016/0022-5096(72)90003-8

12. Jahanandish M, Keshavarz A. Seismic bearing capacity of foundations on reinforced soil slopes. Geotextiles and Geomembranes. 2005;23(1):1-25. https://doi.org/10.1016/j.geotexmem.2004.09.001

13. Kumar J. $N \gamma$ for rough strip footing using the method of characteristics. Canadian Geotechnical Journal. 2003;40(3):669-674. https://doi. org/10.1139/t03-009

14. Lundgren H, Mortensen K. Determination by the theory of plasticity of the bearing capacity of continuous footings on sand. in Proceedings of the Third International Conference on Soil Mechanics and Foundation Engineering. 1953. Zürich, Switzerland.

15. Martin CM. Exact bearing capacity calculations using the method of characteristics. Proc. IACMAG. Turin 2005:441-450.

16. Clausen J. Discussion on "bearing capacity of circular footings over rock mass by using axisymmetric quasi lower bound finite element limit analysis" by Chakraborty $\mathrm{M}$ and Kumar J. Computers and Geotechnics. 2016;73:231-234. https://doi.org/10.1016/j. compgeo.2015.12.002

How to cite this article: Keshavarz A, Kumar J. Bearing capacity of foundations on rock mass using the method of characteristics. Int J Numer Anal Methods Geomech. 2018;42:542-557. https://doi.org/10.1002/nag.2754 